\title{
Pelatihan Penerapan Note-Taking System Untuk Meningkatkan Pemahaman Konsep Bagi Guru SMPIT Madani Pekanbaru
}

\author{
Prih Febtiningsih*, Siti Niah, Wandi Syahfutra, Pahmi, Ardiya, \\ Agung Prasetyo Wibowo \\ Pendidikan Bahasa Inggris, Fakultas Keguruan dan Ilmu Pendidikan \\ Universitas Muhammadiyah Riau \\ email: prihfebtiningsih@umri.ac.id
}

\begin{abstract}
The community service undertaken aims to provide training to the teachers of SMPIT Madani Pekanbaru in order to increase the ability of teachers to understand the concept of material provided by presenters from various sources from seminars, workshops, FGDs or other activities, make it easier for teachers to remember the material presented and be more focused and also help teachers in compiling and processing information obtained through interesting notes so that they are easier to recall what they got in the material delivered by the presenters. To achieve the objectives of this community service (PPM) activity, the implementers used the lecture, discussion and practicum methods so that the trainees could easily understand the material provided at the training. The activities carried out were participated by the teachers at SMPIT Madani Pekanbaru. This activity is on target as evidenced by the enthusiasm of the teacher in following the entire process of activities. They are very active in discussing and interacting when given a material concept and instructing them to take notes with various Note-taking Systems.
\end{abstract}

Keywords: Community Service, Note-taking System, Understanding the Concept

\begin{abstract}
Abstrak
Pengabdian pada masyarakat yang dilakukan bertujuan untuk memberikan pelatihan kepada para guru SMPIT Madani Pekanbaru dengan maksud untuk meningkatkan kemampuan guru dalam memahami konsep materi yang diberikan oleh pemateri dari berbagai sumber baik dari seminar, lokakarya, FGD ataupun kegiatan lainnya, memudahkan guru dalam mengingat materi yang disampaikan dan menjadi lebih fokus dan juga membantu guru dalam menyusun dan memproses informasi yang diperoleh melalui catatan yang menarik sehingga mereka lebih mudah untuk merecall kembali apa yang mereka dapatkan dalam materi yang disampaikan oleh narasumber. Untuk mencapai tujuan dari kegiatan pengabdian pada masyarakat (PPM) ini, maka pelaksana menggunakan metode ceramah, diskusi, dan praktikum agar peserta pelatihan dapat mudah memahami materi yang diberikan pada pelatihan tersebut. Kegiatan yang dilaksanakan diikuti oleh para guru di SMPIT Madani Pekanbaru. Kegiatan ini tepat sasaran yang terbukti dengan antusiasme guru dalam mengikuti seluruh proses kegiatan. Mereka sangat aktif dalam berdiskusi dan berinteraksi ketika diberikan suatu konsep materi dan menginstruksikan mereka untuk membuat catatan dengan berbagai macam Note-taking System.
\end{abstract}

Kata Kunci : Pengabdian kepada Masyarakat, Note-taking System, Pemahaman Konsep.

\section{PENDAHULUAN}

Salah satu aspek penting dalam memahami ilmu pengetahuan adalah pencatatan (Note-taking). Note-taking adalah aktivitas kompleks yang membutuhkan pemahaman dan pemilihan informasi yang tepat dan selanjutnya dituangkan dalam bentuk yang sistematik (Piolat, Olive, dan Kellogg, 2005). Banyak keuntungan utama dari note taking, yaitu note taking berguna saat mengulang kembali konsep materi yang diperoleh dan proses dalam note taking itu sendiri membantu guru memahami materi yang disampaikan (Ward dan Tatsukawa, 2003). Dari sudut 
pandang fisiologi kognitif, note taking adalah aspek dari kebiasaan kompleks manusia yang berhubungan dengan manajemen informasi yang melibatkan proses pemikiran dan interaksinya dengan fungsi kognitif lainnya (Makany, Kemp, dan Dror 2009). Menurut Bouck \& Henderson (2011), metode Note-taking System terdiri dari lima jenis yaitu: Cornell Method, Outlining Method, Mapping Method, Block Method dan Modified Block Method. Masing-masing metode memiliki bentuk yang berbeda.

Kegiatan mencatat (Note taking) adalah keterampilan yang sulit namun penting, terutama mengingat banyaknya materi yang disampaikan dalam kegiatan seminar, lokakarya, pelatihan, FGD ataupun kegiatan lainnya yang harus diikuti oleh para guru agar mereka bisa lebih meningkatkan pengetahuannya. Sebagian besar materi yang disajikan diberikan melalui ceramah. Guru harus mampu mendengarkan dan melihat saat menulis ide-ide utama dan rincian dari materi yang disampaikan, sambil mencocokan informasi baru dengan pengetahuan yang dimiliki sebelumnya untuk pemahaman. Kualitas catatan yang tinggi berkontribusi untuk pemahaman dan review yang lebih baik yang dapat menyebabkan tingkat pengetahuan yang lebih tinggi.

Berdasarkan survey di sekolah SMPIT Madani Pekanbaru, ditemukan bahwa pemahaman konsep suatu materi yang diperoleh dalam kegiatan seminar, pelatihan, lokakarya, FGD ataupun lainnya masih tergolong lemah. Hal ini dikarenakan mereka tidak mempunyai catatan materi yang terstruktur karena mereka belum banyak yang mengetahui Note-taking System yang baik supaya mereka bisa membaca dan mempelajari kembali materi yang disampaikan melalui pencatatan yang mereka lakukan. Selain itu, guru susah mengingat kembali materi yang disampaikan oleh narasumber sehingga ketika ditanya kembali mereka mendapatkan kesulitan dalam menjawab pertanyaan tersebut. Perlu adanya suatu pencatatan yang baik yang dapat digunakan untuk memahami konsep materi. Oleh karena itu, dilakukanlah Pelatihan Penerapan Note-Taking System untuk Meningkatkan Pemahaman Konsep bagi Guru SMPIT Madani Pekanbaru.

\section{METODE PENGABDIAN}

Materi pelatihan dibuat sesuai kebutuhan mitra pengabdian. Materi yang disampaikan pada "Pelatihan Penerapan Note-Taking System untuk Meningkatkan Pemahaman Konsep bagi Guru SMPIT Madani Pekanbaru” yaitu tentang bagaimana kemampuan guru dalam memahami konsep dengan menggunakan Note-taking System sehingga diharapkan dapat meningkatkan kemampuan mereka dalam memahami konsep materi yang disampaikan oleh narasumber.

Metode yang digunakan dalam kegiatan pelatihan ini adalah metode ceramah, diskusi dan praktikum. 1) Metode Ceramah digunakan untuk menyampaikan materi secara rinci tentang bagaimana kemampuan guru dalam memahami konsep dengan metode Note-taking System 2) Metode diskusi digunakan untuk melakukan tanya jawab dari pertanyaan yang muncul tentang materi yang telah disampaikan. 3) Metode praktikum digunakan untuk memberikan pengalaman secara langsung kepada peserta bagaimana menerapkan Notetaking System sehingga peserta pelatihan dapat memahami secara langsung bagaimana strategi mereka dalam memahami konsep dengan baik.

Pada proses pelaksanaannya, kegiatan pengabdian diawali dengan perkenalan antara Tim pelaksana dengan 
peserta pengabdian yaitu Guru SMPIT Madani Pekanbaru yang dilanjutkan dengan pengenalan materi kepada peserta latihan. Kemudian, Tim pelaksana melakukan kegiatan proses pelatihan untuk meningkatkan kemampuan pemahaman konsep guru dengan baik melalui Note-Taking System. Setelah itu, dilakukan review untuk menegaskan kembali materi pelatihan yang sudah disampaikan. Kegiatan pengabdian kepada masyarakat ini dilakukan pada bulan November 2019, Desember 2019 dan Januari 2020. Adapun rancangan jadwal pelaksanaan kegiatan pengabdian adalah sebagai berikut:

Tabel 1 : Jadwal Kegiatan

\begin{tabular}{|r|l|l|l|l|}
\hline \multirow{2}{*}{ No } & \multicolumn{1}{|c|}{ Kegiatan } & \multicolumn{3}{|c|}{ Bulan } \\
\cline { 3 - 5 } & & Nov & Des & Jan \\
\hline 2 & $\begin{array}{l}\text { Lokakarya } \\
\text { Orientasi } \\
\text { mengenai Note- } \\
\text { taking System }\end{array}$ & $\begin{array}{l}\text { Lokakarya } \\
\text { penerapan Note- } \\
\text { taking System } \\
\text { dalam } \\
\text { memahami } \\
\text { konsep }\end{array}$ & & \\
\hline 3 & $\begin{array}{l}\text { Lokakarya } \\
\text { Praktek } \\
\text { penerapan Note- } \\
\text { taking System }\end{array}$ & & & \\
\hline
\end{tabular}

\section{HASIL DAN PEMBAHASAN}

Setelah melaksanakan kegiatan Pengabdian kepada Masyarakat, terlihat bahwa kegiatan tersebut tepat sasaran yang terbukti dengan antusiasme guru dalam mengikuti seluruh proses kegiatan. Mereka sangat aktif dalam berdiskusi dan berinteraksi ketika diberikan suatu konsep materi dan menginstruksikan mereka untuk membuat catatan dengan berbagai macam Note-taking System. Pelatihan ini dapat dilihat pada gambar 1.

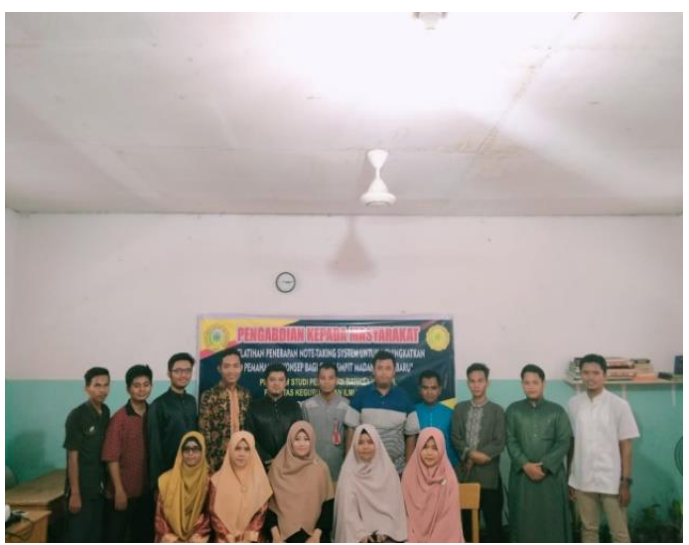

\section{Gambar 1. Peserta Pelatihan}

Kegiatan pengabdian ini dilakukan pada bulan November 2019 - Januari 2020. Pada bulan November 2019, kegiatan pengabdian ini dimulai dengan pembukaan oleh Ketua Program Studi Pendidikan Bahasa Inggris. Kemudian, dilanjutkan dengan kegiatan perkenalan dan pendekatan antara pelaksana dengan peserta sebagai mitra kegiatan pengabdian masyarakat. Selanjutnya, tim pelaksana memberikan orientasi mengenai Note-taking System. Tim pelaksana melakukan warming up terlebih dahulu dengan memberikan pertanyaan-pertanyaan yang berkaitan dengan Note-taking System. Setelah dilakukan warming up, tim pelaksana menjelaskan materi mengenai Notetaking System seperti definisi, tujuan, manfaat, jenis-jenis Note-taking System. Tim pelaksana menampilkan bentukbentuk Note-taking System. Ketika menjelaskan materi Note-taking System, guru terlihat tertarik karena sebelumnya mereka hanya melakukan pencatatan dengan jenis catatan yang biasa saja.

Pada bulan Desember 2019, guru diberikan contoh cara menerapkan Notetaking System. Di dalam pemberian contoh penerapannya, tim pelaksana memperlihat-kan contoh pencatatan (Note-taking System) dari sebuah materi seperti Cornell Method, Outlining Method, Mapping Method, Block Method dan Modified Block Method. 
Pada bulan Januari 2020, tim pelaksana memberikan kesempatan kepada guru-guru untuk membuat catatan dengan berbagai jenis Notetaking System seperti Cornell Method, Outlining Method, Mapping Method, Block Method dan Modified Block Method. Mereka menerapkan sistem pencatatan secara berkelompok yang tiap kelompoknya terdiri dari dua orang. Mereka melakukan pencatatan dari materi yang disampaikan oleh tim pelaksana. Setelah mereka membuat catatan bersama kelompoknya, tim pelaksana mengecek hasil catatan mereka dengan memperlihatkan hasil pencatatan mereka kepada kelompok lainnya sehingga mereka bisa saling memberikan masukan atau saran satu sama lain. Guru-guru sungguh antusias mengikuti pelatihan karena mereka mendapatkan pengetahuan yang sebelumnya mereka belum ketahui karena selama ini mereka hanya melakukan pencatatan secara konvensional saja. Oleh karena itu, diharapkan setelah mereka mengikuti pelatihan ini mereka dapat menerapkan pencatatan yang lebih baik lagi, lebih terstruktur dan terorganisir.

\section{SIMPULAN}

Berdasarkan pembahasan yang telah dijabarkan sebelumnya, dapat disimpulkan bahwa penerapan Notetaking System dapat menarik perhatian guru dalam melakukan pencatatan sehingga mereka dapat memahami materi yang disampaikan dengan baik Kegiatan pengabdian ini tepat sasaran yang terbukti dengan antusiasme guru dalam berdiskusi dan berinteraksi dengan kelompoknya. Mereka sangat tertarik dan aktif dalam melakukan pencatatan dengan berbagai jenis Notetaking System. Suasana menjadi tertib dan terkendali karena pikiran guru terpusat pada sistem pencatatan yang lebih terstruktur dan terlihat menarik.
Dengan diadakannya kegiatan Pengabdian kepada Masyarakat ini, tim pelaksana dari Program Studi Pendidikan Bahasa Inggris UMRI juga dapat menjalankan catur dharma perguruan tinggi dimana salah satu perannya adalah dengan melaksanakan Pengabdian kepada Masyarakat.

\section{UCAPAN TERIMA KASIH}

Kegiatan pengabdian kepada masyarakat ini dapat terlaksana berkat dukungan dari berbagai pihak yang telah membantu secara materil dan moril sehingga kegiatan pengabdian ini dapat terlaksana dengan baik. Oleh sebab itu, dalam kesempatan ini perkenankan penulis menyampaikan ucapan terima kasih kepada:

1. Rektor UMRI

2. Ketua LPPM UMRI

3. Dekan FKIP UMRI

4. Ketua Program Studi Pendidikan Bahasa Inggris

5. Kepala SMPIT Madani Pekanbaru

6. Majelis Guru SMPIT Madani Pekanbaru

\section{DAFTAR PUSTAKA}

[1] Bauer A, Koedinger KR. 2007. Selection-Based Note-Taking Applications. CHI ${ }^{e 0} 07$ Proceedings of the SIGCHI Conference on Human Factors in Computing Systems. 981-90.

[2] Bouck, C. \& Henderson, K. (2011). Transition Planning Considerations: A Strategy for Note taking - A PowerPoint Presentation for Professional Development. Modules Addressing Special Education and Teacher Education (MAST). Greenville, NC: East Carolina University.

[3] Makany T, Kemp J, Dror IE. 2009. Optimising the Use of Note-taking as an External Cognitive Aid for Increasing 
ISSN : 2550-0198

Learning. British Journal of Educational Technology. 40(4):619-35

[4] Piolat A, Olive T, Kellogg RT. 2005. Cognitive Effort During Notetaking. Applied Cognitive Psychology. 19(3):291-312

[5] Ward N, Tatsukawa H. 2003. A Tool for Taking Class Notes. International Journal of Human Computer Studies. 59(6):959-81 